\title{
INVESTIGATING THE RESETTING OF OSL SIGNALS IN ROCK SURFACES
}

\author{
REZA SOHBATI ${ }^{1}$, ANDREW S. MURRAY ${ }^{1}$, MAYANK JAIN ${ }^{2}$, JAN-PIETER BUYLAERT ${ }^{1,2}$ \\ and KRISTINA J. THOMSEN ${ }^{2}$

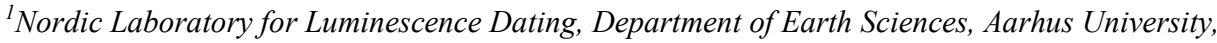 \\ Risø DTU, DK-4000 Roskilde, Denmark \\ ${ }^{2}$ Radiation Research Division, Risø National Laboratory for Sustainable Energy, Technical University of Denmark, \\ DK-4000 Roskilde, Denmark
}

Received 24 February 2010

Accepted 15 December 2010

\begin{abstract}
There are many examples of buried rock surfaces whose age is of interest to geologists and archaeologists. Luminescence dating is a potential method which can be applied to dating such surfaces; as part of a research project which aims to develop such an approach, the degree of resetting of OSL signals in grains and slices from five different cobbles/boulders collected from a modern beach is investigated. All the rock surfaces are presumed to have been exposed to daylight for a prolonged period of time (weeks to years). Feldspar was identified as the preferred dosimeter because quartz extracts were insensitive. Dose recovery tests using solar simulator and IR diodes on both K-feldspar grains and solid slices taken from the inner parts of the rocks are discussed. Preheat plateau results using surface grains and slices show that significant thermal transfer in naturally bleached samples can be avoided by keeping preheat temperatures low. Equivalent doses from surface K-feldspar grains were highly scattered and much larger than expected $(0.02 \mathrm{~Gy}$ to $>100 \mathrm{~Gy})$, while solid surface slices gave more reproducible small doses (mean $=0.17 \pm 0.02 \mathrm{~Gy}, \mathrm{n}=32$ ). Neither crushing nor partial bleaching were found to be responsible for the large scattered doses from grains, nor did the inevitable contribution from Na-feldspar to the signal from solid slices explain the improved reproducibility in the slices. By modelling the increase of luminescence signal with distance into the rock surface, attenuation factors were derived for two samples. These indicate that, for instance, bleaching at a depth of $2 \mathrm{~mm}$ into these samples occurs at about $\sim 28 \%$ of the rate at the surface. We conclude that it should be possible to derive meaningful burial doses of $>1$ Gy from such cobbles; younger samples would probably require a correction for incomplete bleaching.
\end{abstract}

Keywords: bleaching, luminescence, rock surfaces, feldspar, OSL, IRSL.

\section{INTRODUCTION}

In geology and archaeology there are many examples of rock surfaces, rock art and stone structures of unknown age. In archaeology, megaliths, chambered burial mounds, field walls, and cairns are very important to our

Corresponding author: R. Sohbati

e-mail: resih@risoe.dtu.dk understanding of the way in which people used the landscape. In geology, there are examples of ice-scoured bedrock, ice-transported rocks (erratics), and cobble fans from extreme fluvial events whose ages are essential for understanding the evolution of the driving phenomena. There are two potential and complementary methods for dating such surfaces: cosmogenic radionuclides can be used to date the time of exposure of the rock face on the 
surface of the earth, and the build up of trapped charge (measured e.g. by luminescence) can give the age since a previously daylight-exposed surface was buried in the ground. The latter approach requires that any previous latent luminescence signal be reset (or zeroed or bleached) before burial.

Early studies of the luminescence dating of rock surfaces used the thermoluminescence (TL) signal from calcitic rocks (e.g. Liritzis, 1994; Liritzis et al., 1997; Theocaris et al., 1997; Polikreti et al., 2003), but even after long exposures to sunlight, there remains a significant residual TL signal (Liritzis and Galloway, 1999); this significantly limits the youngest ages that can be determined using this method. To circumvent this problem, later studies (Habermann et al., 2000; Greilich et al., 2005; Vafiadou et al., 2007; Liritzis et al., 2007; 2008) have investigated the potential of the optically stimulated luminescence signal (OSL or IRSL); this bleaches to a much lower level than TL signals; in sediment dating, luminescence ages of as young as a few years can be derived (e.g. Madsen and Murray, 2009). However, no routine approach to the OSL dating of rock surfaces has yet been developed.

In the luminescence dating of solid rocks, one important question is which mineral should be chosen as the dosimeter. The most common dosimeter minerals used in luminescence dating of sediments are quartz and Kfeldspar; these have different advantages and disadvantages. For instance, quartz is easily bleached and the luminescence signal is apparently stable, while $\mathrm{K}$ feldspar bleaches more slowly (Huntley and Lamothe, 2001; Klasen et al., 2006) and suffers from athermal loss of signal (anomalous fading) (Aitken, 1985; Spooner, 1994). The sensitivity of quartz is variable and at least in part depends on lithology (e.g. Tsukamoto et al., 2011) whereas K-feldspar is usually sensitive (Huntley and Lamothe, 2001). There is also an important difference in dosimetry: quartz has almost no internal radioactivity (and Na-feldspar only a little) but K-feldspar can contain up to $14 \%$ potassium, of which one isotope $\left({ }^{40} \mathrm{~K}\right)$ is radioactive. The dose rate contribution from this internal activity can make up $\sim 30 \%$ of the total for sand-sized grains. For all minerals the external beta dose rate decreases with grain size (because of attenuation), but for K-rich feldspar the internal beta dose rate increases (because more of the decay energy is absorbed within the grain). In the latter case, the net effect is an increase of total dose rate with grain size. Representative curves showing these relationships are given in Fig. 1, from which it can be seen that the total beta dose rate to quartz and Na-feldspar have the weakest dependence on grain size. From this perspective at least, this makes it easier to calculate an accurate dose rate (and thus age) for these minerals.

The broad aim of our research is to come up with a routine method for the luminescence dating of hard-rock surfaces. Here we report on an investigation of the completeness of natural bleaching of daylight-exposed rock surfaces; this forms the first part of our study. Both grains and solid slices taken from cobbles/boulders of various lithologies collected from a modern beach are employed. We first consider which natural luminescent mineral is most likely to be generally useful for the dating of rocks, and then investigate the degree of daylight resetting of OSL signals on and into these rock surfaces.

\section{SAMPLES AND SAMPLE PREPARATION}

Five different cobble-sized rocks $(\sim 30 \mathrm{~cm}$ in diameter) were collected from a local beach (Table 1). All were exposed to daylight at the time of collection, and due to the activity of the beach environment it is likely that all the surfaces of these rocks have been exposed to daylight for a prolonged period, certainly many days, and probably many weeks to years. Under red-orange light conditions cores $\sim 10 \mathrm{~mm}$ in diameter and up to $40 \mathrm{~mm}$ long were drilled from the surfaces of the cobbles and cut into $\sim 1 \mathrm{~mm}$ thick slices using a water-cooled diamond wafer blade of thickness $0.3 \mathrm{~mm}$. In some cases (see section 3), the slices were crushed by hand in an agate mortar, and the grain size fraction $63-250 \mu \mathrm{m}$ separated by dry sieving. Quartz- and feldspar-rich extracts were then separated in the usual manner using heavy liquids $(\rho=2.62$ $\mathrm{g} / \mathrm{cm}^{3}$ ), and K-rich and Na-rich feldspar separated using $\rho=2.58 \mathrm{~g} / \mathrm{cm}^{3}$.

Table 1. Rock samples (n/a - not available).

\begin{tabular}{ccc}
\hline Sample Code & Rock type & Bulk dose rate (Gy/ka) \\
\hline 099901 & Coarse-grained granite & $6.07 \pm 0.09$ \\
099902 & Metamorphosed granite & $4.56 \pm 0.19$ \\
099903 & Metamorphosed sediment & $\mathrm{n} / \mathrm{a}$ \\
099906 & Fine-grained granite & $\mathrm{n} / \mathrm{a}$ \\
099911 & Gneiss & $\mathrm{n} / \mathrm{a}$ \\
\hline
\end{tabular}

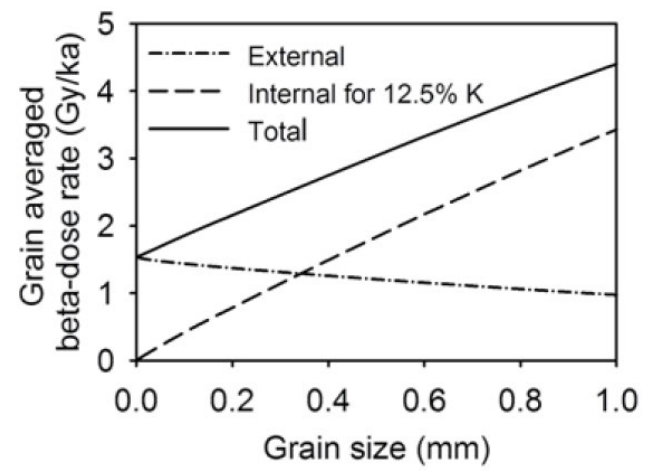

Fig. 1. Dependence of internal beta dose rate on grain size for $12 \mathrm{ppm}$ Th, $3 \mathrm{ppm} U$, and $2 \% \mathrm{~K}_{2} \mathrm{O}$ of radionuclide concentrations averaged over the entire volume of a grain (modified from Mejdahl, 1979). The dependence of these representative curves on the U/Th/K is small, and discussed by Mejdahl (1979). 
Solid rock slices were cleaned in 10\% HF for $40 \mathrm{~min}$ and $10 \% \mathrm{HCl}$ for $20 \mathrm{~min}$. Quartz-rich grains were etched in concentrated HF acid for 60 min to dissolve the alphairradiated surface layer and to remove any residual feldspar grains. Any fluoride contamination was then removed using a $10 \% \mathrm{HCl}$ solution for $40 \mathrm{~min}$. K-rich feldspar grains were cleaned using $10 \% \mathrm{HF}$ for $40 \mathrm{~min}$ and $10 \% \mathrm{HCl}$ for $20 \mathrm{~min}$.

All measurements were made using a Risø TL/OSL reader (models TL-DA 8 and 12) with blue light stimulation $\left(\lambda=470 \mathrm{~nm}, \sim 50 \mathrm{~mW} . \mathrm{cm}^{-2}\right)$ and photon detection through a $7.5 \mathrm{~mm}$ Schott U-340 glass filter for quartz. Infra-red stimulation $\left(\lambda=875 \mathrm{~nm}, \sim 100 \mathrm{~mW} . \mathrm{cm}^{-2}\right)$ and photon detection through a Schott BG39/Corning 7-59 filter combination ( 2 and $4 \mathrm{~mm}$, respectively) was used for feldspar. Beta irradiations used a calibrated (using $180-250 \mu \mathrm{m}$ quartz grains) ${ }^{90} \mathrm{Sr} /{ }^{90} \mathrm{Y}$ source mounted on the reader (Bøtter-Jensen et al., 2003). Grains were mounted as large or small aliquots in a monolayer using silicone oil on $8 \mathrm{~mm}$ diameter stainless steel cups; solid slices were placed directly on the turntable without any additional backing.

Bulk dose rates have also been measured for 2 samples using high resolution gamma spectrometry (Murray et al., 1987). The results are given in Table 1.

\section{LUMINESCENCE CHARACTERISTICS}

\section{Quartz sensitivity}

Because of its desirable characteristics, quartz is the most widely-used dosimeter in luminescence dating. Quartz extracts from three different samples (Granite099901, meta-granite -099902, and meta-sedimentary099903, see Table 1) were tested for their luminescence sensitivity by mounting grains extracted from surface slices on stainless steel cups as large aliquots $(\sim 8 \mathrm{~mm}$ diameter). A dose of $\sim 8 \mathrm{~Gy}$, followed by a preheat of $180^{\circ} \mathrm{C}$ was used before OSL measurement. Representative decay curves from such a dose are shown for samples 099901 and 099902 in Fig. 2a, b; it is clear that there is no significant blue-stimulated OSL signal from these grains. Unfortunately, this is not unusual for quartz extracted from primary rocks (Moska and Murray, 2006; Tsukamoto et al., 2011), and it is clear that one cannot in general expect to extract sensitive quartz from magmatic/metamorphic rock samples. However, this is not universal; Tsukamoto et al. (2011) argue that the quartz sensitivity is a function of the geological age of the rock, and at least some secondary rocks (sandstones etc.) are known to contain sensitive quartz grains. Nevertheless, these observations seem to preclude the widespread use of quartz extracts from rock surfaces as dosimetric material.

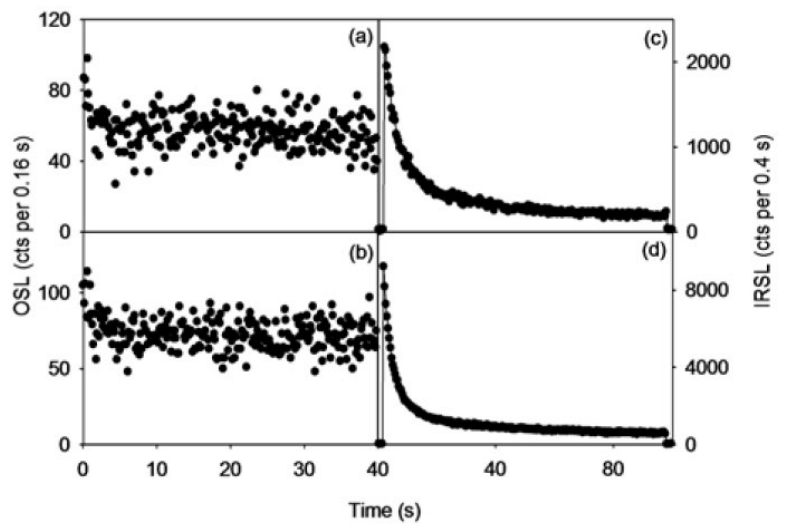

Fig. 2. Typical decay curves for quartz $(a, b)$ and K-feldspar (c, d) extracts from samples 099901 (a, c) and 099902 (b, d) following a test dose of $\sim 8 \mathrm{~Gy}$. Quartz was measured after a cut-heat to $180^{\circ} \mathrm{C}$ and $\mathrm{K}$ feldspar after a preheat to $200^{\circ} \mathrm{C}$ for $60 \mathrm{~s}$.

\section{K-feldspar sensitivity}

Because of the considerable literature on the luminescence characteristics of K-feldspar, we decided next to investigate K-rich feldspar extracts, despite their less favourable dosimetric characteristics.

K-rich feldspar grains extracted from surface slices were mounted in stainless steel cups as small aliquots ( $\sim 2 \mathrm{~mm}$ diameter) using silicone oil. A dose of $\sim 8 \mathrm{~Gy}$ was used, followed by a preheat of $200^{\circ} \mathrm{C}$ for $60 \mathrm{~s}$ before OSL measurement. In contrast to quartz, K-rich feldspar extracts from two different rock samples were sensitive (typical curves shown in Fig. 2c, d), and this is representative of 4 out of 5 samples examined. It appears that significant feldspar IRSL sensitivity may be more likely to be available from primary rocks than significant quartz OSL sensitivity.

\section{SAR performance}

Fig. 3a (3b is discussed in section 4) shows a typical growth curve measured using a SAR IRSL protocol with the same thermal treatment $\left(200^{\circ} \mathrm{C}\right.$ for $\left.60 \mathrm{~s}\right)$ following the regenerative dose and the test dose (Blair et al., 2005). The stimulation was carried out at $50^{\circ} \mathrm{C}$ for $100 \mathrm{~s}$ using IR diodes, and each cycle ended with stimulation at $290^{\circ} \mathrm{C}$ for $100 \mathrm{~s}$ to minimise recuperation (Buylaert et al., 2007; Wallinga et al., 2007). The measurements are reproducible (see repeat point at $0.8 \mathrm{~Gy}$ ), and the curve passes close to the origin, indicating that our SAR protocol is able to reproducibly measure laboratory doses (for doses given after the sample has been preheated to measure the natural signal).

To investigate the applicability of our SAR protocol to the measurement of doses given before any heating (and thus, by implication, to the measurement of the natural dose) a dose recovery test was carried out at dif- 


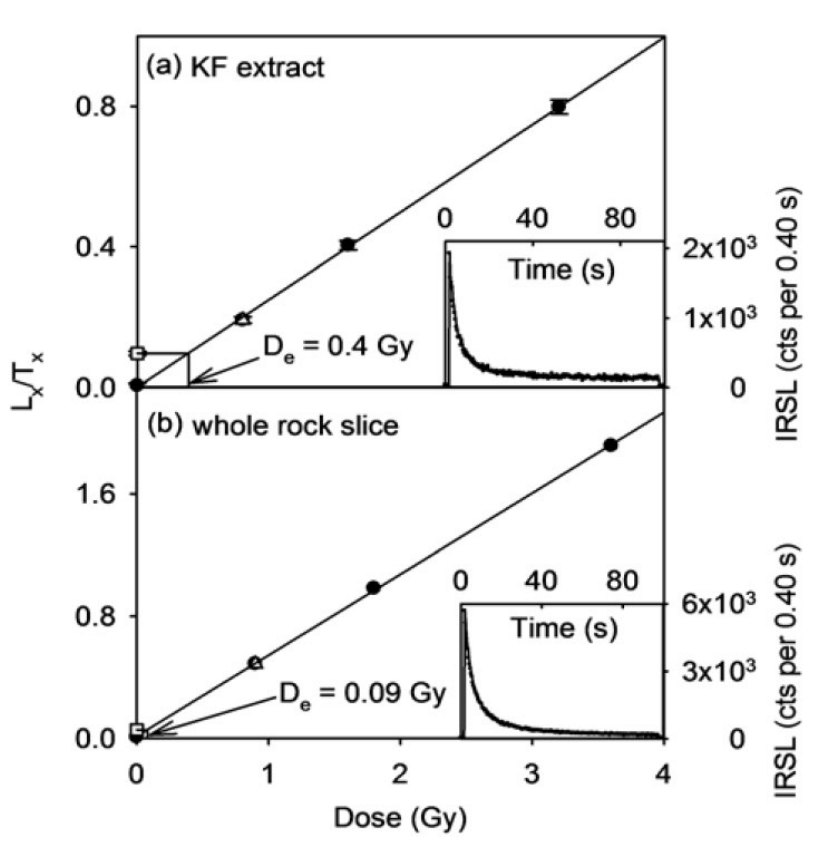

Fig. 3. Typical growth and decay (inset) curves for a K-rich feldspar extract (a) and a solid rock slice (b) from sample 099902.

ferent preheat temperatures on K-feldspar extracts from sample 099902 (Wallinga et al., 2000). K-feldspar extracts, from inner slices of the rock samples (i.e. not from the surface) were first optically bleached to give aliquots with little or no residual luminescence signal. As there is no general agreement on the best approach to bleaching feldspars in the laboratory (Buylaert et al., 2009), we bleached the samples in two different ways. In the first method aliquots were bleached in a Hönle SOL2 solar simulator at room temperature for $\sim 4 \mathrm{~h}$ at a distance of $\sim 1 \mathrm{~m}$ from the light source; in the second, different aliquots were bleached in the reader using IR light at room temperature for $1000 \mathrm{~s}$. After bleaching, the residual doses in three aliquots were measured at eight different preheat temperatures from 130 to $270^{\circ} \mathrm{C}$ with increments of $20^{\circ} \mathrm{C}$. In both cases (daylight simulator and IR bleaching) the residuals show a smooth increase with preheat temperature (Fig. 4a). After solar simulator bleaching, the residual doses vary from $2.17 \pm 0.06$ to $4.5 \pm 0.4 \mathrm{~Gy}$ comparable to those reported by Liritzis et al., (2008), and after bleaching by IR diodes from $1.20 \pm 0.03$ to $3.88 \pm 0.03 \mathrm{~Gy}$. On average, the residuals in samples bleached by IR diodes are $\sim 1$ Gy smaller than those bleached by the solar simulator. Since it is unlikely that shorter wavelengths are actually less effective at emptying traps in feldspar, it may be that the shorter wavelengths are also transferring charge from deeper traps into the IR sensitive traps, thus making it appear to be more difficult to empty.

For the dose recovery test itself, two further sets of aliquots were bleached in the same manner as for the



Fig. 4. a) Residual doses and (b) dose recovery ratios for different preheat temperatures for K-feldspar extracts from sample 099902 after bleaching by solar simulator for $\sim 4 \mathrm{~h}$ (circles) and IR diodes for $1000 \mathrm{~s}$ at room temperature (triangles). Error bars show one standard error.

measurement of residuals. These bleached samples were then given a dose of $\sim 80 \mathrm{~Gy}$; this dose was chosen because: 1) the grains used for dose recovery test were taken from slices coming from the inner part of the rocks, and so were expected to have high natural doses; 2) we wanted to recover a dose which was well above the residuals (2-4 Gy). Three aliquots were measured at each preheat temperature. The ratio of the average measured dose (less the appropriate average residual dose) to the given dose was calculated for each temperature (Fig. 4b). The ratios decrease from $0.87 \pm 0.01$ to $0.73 \pm 0.02$ and $0.85 \pm 0.01$ to $0.64 \pm 0.02$ for solar simulator and IR bleached aliquots respectively, indicating that we seem to be unable to accurately measure a known dose in these materials using our SAR protocol, if the dose is given before any thermal treatment.

Despite the poor results from the dose recovery tests, preheat plateaus were measured using K-feldspar extracts from surface slices for samples 099902 and 099906 (Fig. 5a, b; 3 aliquots per temperature). In these naturally bleached samples there is no significant effect of thermal transfer at preheat temperatures of $150^{\circ} \mathrm{C}(099906)$ or $190^{\circ} \mathrm{C}(099902)$ or less. The distribution of equivalent doses (inset to Fig. 5a; only showing data up to $190^{\circ} \mathrm{C}$ ) shows the presence of several high dose outliers for sample 099902. The mean $D_{e}$ value for this sample is $0.14 \pm 0.03$ Gy $(\mathrm{n}=39)$ for preheat temperatures below $190^{\circ} \mathrm{C}$ (excluding 9 outliers). For sample 099906 the mean $D_{e}$ is $0.14 \pm 0.02$ Gy $(n=15)$ for preheat temperatures of $150^{\circ} \mathrm{C}$ and below. 


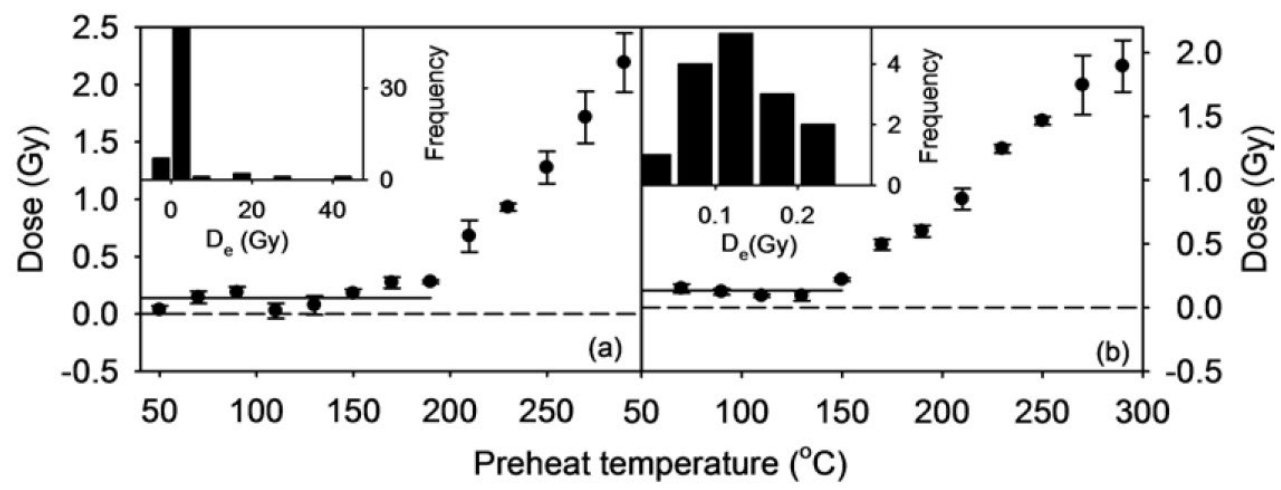

Fig. 5. Preheat plateau of K-feldspar extracts from surface slices for samples 099902 (a) and 099906 (b). The insets show the distribution of doses. Uncertainties represent one standard error.

\section{Equivalent dose $\left(D_{e}\right)$ measurements}

The equivalent doses recorded by K-feldspar grains extracted from surface slices were measured using the same SAR protocol as above, but with a fixed preheat of $200^{\circ} \mathrm{C}$ for $60 \mathrm{~s}$ at which the effect of thermal transfer is insignificant. Fig. 6 presents the distribution of equivalent doses from rock surfaces for four different samples (including data from insets to Figs. 5a, b for preheat temperatures below $190^{\circ} \mathrm{C}$ and $150^{\circ} \mathrm{C}$ respectively). The results differ significantly from sample to sample; for samples 099901 and 099911 the $\mathrm{D}_{\mathrm{e}}$ values are much larger than those from 099902 and 099906. It is also noteworthy that for sample 099902, there are some large outliers in the distribution of doses which increase the mean value considerably. The wide range of surface doses $(0.02$ to $195 \mathrm{~Gy})$ and their significant difference from sample to sample are not consistent with our expectation that these surfaces have recently been exposed to light for a prolonged period. Morgenstein et al. (2003) have also reported natural doses larger than expected from fine grain feldspar fractions scraped off the rock surfaces. However, these highly scattered large doses from feldspar grains extracted from rock surfaces are in contrast to earlier published results using solid slices which reported credibly small natural doses for surface samples (Vafiadou et al., 2007; Greilich et al., 2005). Therefore, we decided to repeat our measurements on uncrushed slices.

\section{WHOLE ROCK SLICES}

To allow comparison between the results from grains extracted from surface slices and solid surface slices, IRSL signals from slices were measured in the same manner as those from K-feldspar grains (see section 3.3), except that to ensure that the slices had reached the stimulation temperature, a pause of $30 \mathrm{~s}$ was inserted after heating to $50^{\circ} \mathrm{C}$. Signals were also recorded before and after optical stimulation to monitor any thermolumi-

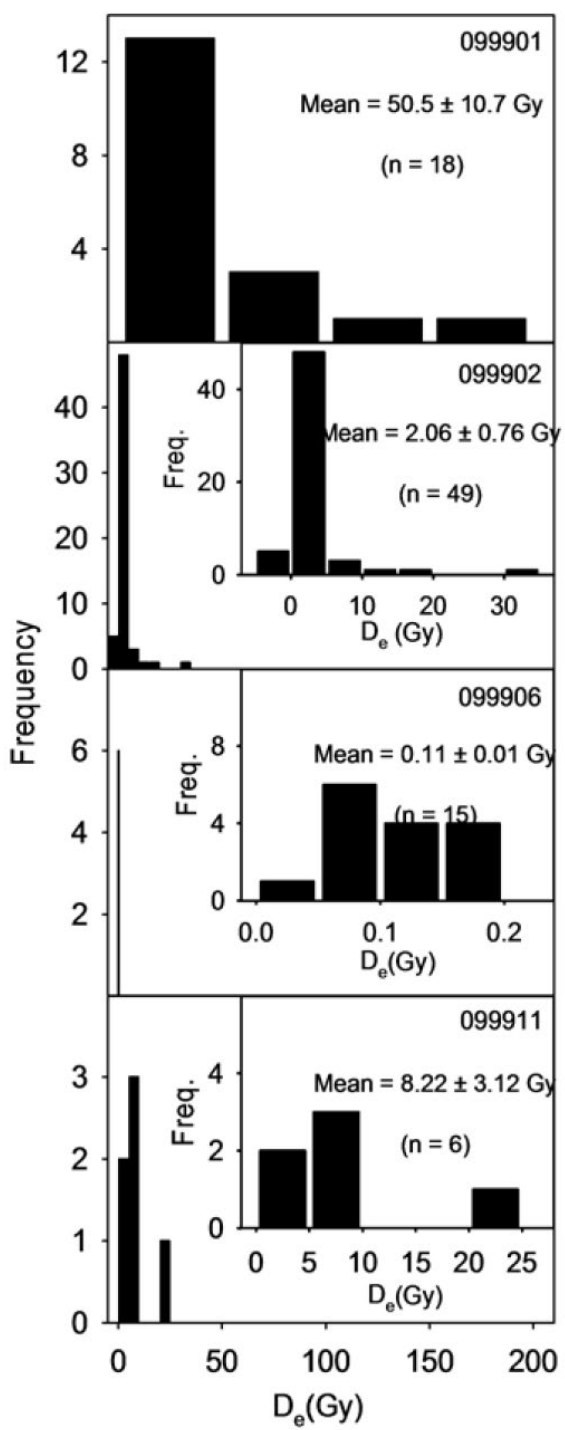

Fig. 6. Distribution of equivalent doses from K-feldspar extracts from surface slices. Insets show the distributions with higher resolution. 
nescence signals. Representative decay and growth curves for a solid slice from sample 099902 are shown in Fig. 3b (the decay curve is a response to a test dose of $\sim 1.8 \mathrm{~Gy}$ after heating to $200^{\circ} \mathrm{C}$ for $60 \mathrm{~s}$ ). The signal is strong and decays with time in a similar manner to that of the IRSL curves from K-rich feldspar grains (insets to Fig. 3a, b). The growth curve passes through the origin and the recycling ratio is $1.00 \pm 0.02$ indicating that laboratory doses given after heating can be measured reproducibly using our SAR protocol.

\section{SAR performance and $D_{e}$ measurements}

As with grains, a dose recovery test was carried out on inner slices from sample 099906. Solid slices were bleached in a Hönle SOL2 solar simulator for $\sim 4 \mathrm{~h}$, and then their residuals were measured at different preheat temperatures (Fig. 7a). Three slices were measured per preheat temperature. As with K-feldspar grains the residuals are significant and increase smoothly from $1.88 \pm 0.02 \mathrm{~Gy}$ at $130^{\circ} \mathrm{C}$ to $4.02 \pm 0.03 \mathrm{~Gy}$ at $270^{\circ} \mathrm{C}$. Additional slices were bleached in a similar way, given a dose of $\sim 90 \mathrm{~Gy}$ (for the same reason as for grains), and measured in the usual manner ( 3 slices per preheat temperature). The given to measured dose ratios were calculated as above (Fig. 7b). They decrease from $0.89 \pm 0.02$ to $0.75 \pm 0.03$ for the lowest and highest preheat temperatures respectively, similar to the dose recovery ratios from K-feldspar grains.

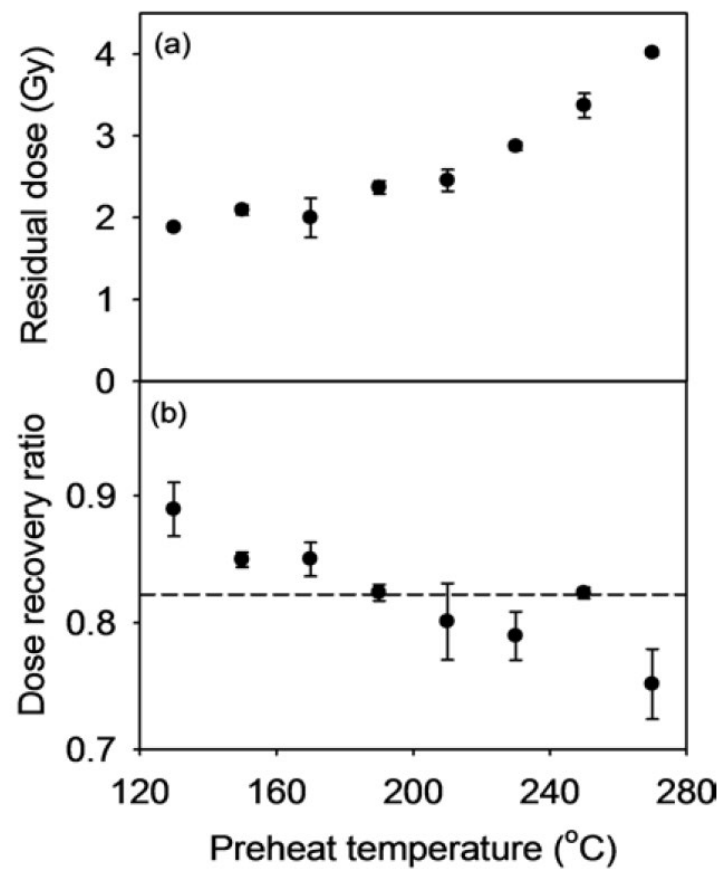

Fig. 7. a) Residual doses and b) dose recovery ratios for different preheat temperatures for whole rock slices from sample 099906 after bleaching by solar simulator for $\sim 4 \mathrm{~h}$. Error bars represent one standard error.
A preheat plateau test was performed on solid surface slices from sample 099906. As for K-feldspar grains, there is apparently no significant thermal transfer at preheat temperatures below $180^{\circ} \mathrm{C}$ (Fig. 8). The inset shows the distribution of doses up to this preheat temperature. All the values are less than $1 \mathrm{~Gy}$, and the average value is $0.13 \pm 0.02$ Gy $(\mathrm{n}=18)$.

Fig. 9a shows the distribution of equivalent doses from surface slices; all provided very similar small doses $(<1 \mathrm{~Gy})$, and so results from all samples are summarised in the same figure. The average of all $\mathrm{D}_{\mathrm{e}}$ values measured from surface slices is $0.17 \pm 0.02$ Gy $(\mathrm{n}=32$; relative standard deviation $77 \%$ ) which is to be contrasted with the larger mean value $(9.5 \pm 3.5 \mathrm{~Gy} ; \mathrm{n}=126)$ and the much more scattered results $(\mathrm{rsd}=264 \%)$ from all $\mathrm{K}$ feldspar extracts. In the next section, we investigate the reasons for this difference.

\section{Investigating the origins of the large, highly scattered doses from surface K-feldspar grains}

There are three possible explanations for the different behaviour of solid slices and grain extracts. The first (i) arises from the attenuation of light as it penetrates the rock. If the intensity gradient is very steep compared to the thickness of a slice $(1 \mathrm{~mm})$, grains at the back of the slice would not receive the same amount of light exposure as surface grains. Then, by crushing the slices, we mix the fully bleached surface grains with partially bleached grains from the back of the slice, resulting in an increased residual dose, and a larger scatter. Secondly, (ii) the act of crushing may produce a variable and non radiation-induced luminescence signal, thus increasing the apparent residual dose. Finally (iii) Na-feldspar or other IR sensitive minerals present in the solid slices may bleach to lower levels or fade more quickly than Kfeldspar grains in nature. In that case, their contribution to the signals induced by laboratory regenerative doses

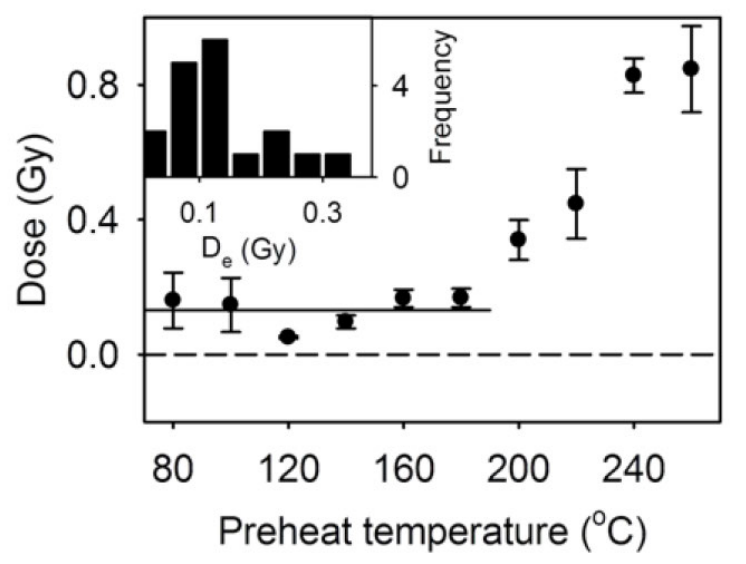

Fig. 8. Preheat plateau of surface slices from sample 099906. The inset shows the distribution of surface doses. Uncertainties show one standard error. 


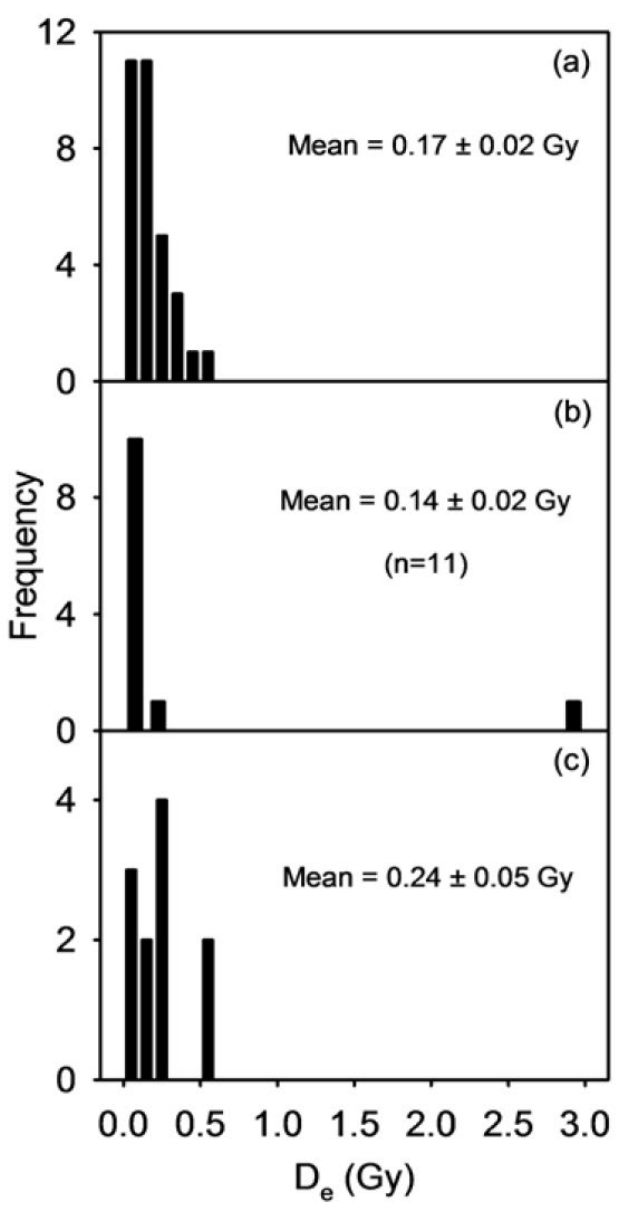

Fig. 9. Distribution of equivalent doses from a) whole-rock surface slices, b) crushed measured slices, and c) inverted surface slices from different samples.

could lead to a reduction in the average apparent natural doses recorded by the slices.

\section{Inverted slices}

To investigate the possible contribution of the grains at the back of the slices to the scattered distribution of surface doses, new surface slices were prepared from various samples; these were then placed upside down on the wheel (such that the daylight exposed face was furthest from the stimulation and detection system) and measured in the usual manner. Fig. 9b shows the distribution of doses from these inverted slices. Excluding one outlier $\left(\mathrm{D}_{\mathrm{e}}=2.96 \mathrm{~Gy}\right)$ in the distribution, the average dose is $0.14 \pm 0.02$ Gy $(n=11)$ which suggests that the grains at the back of the slices are as well bleached as grains on the rock surface, and that daylight attenuation over a short distance of $\sim 1 \mathrm{~mm}$ is not significant.

\section{Effect of crushing}

To examine the possible effect of crushing, previously measured slices from samples 099901, 099902, and 099903 were crushed (at least three slices were crushed per sample). The crushed material was mounted on stainless steel cups and measured as usual. As a result of the bleaching during measurement, one can be confident that they did not record any significant dose before crushing, and therefore any residual dose measured after grain separation was likely to have been induced mainly by the crushing process. Fig. 9c shows the resulting distribution of doses. The narrow distribution of the doses (all of them are less than $1 \mathrm{~Gy}$ ) and their small average value $(0.24 \pm 0.05 \mathrm{~Gy}, \mathrm{n}=11)$ show that crushing alone cannot be responsible for the highly scattered, large doses from $\mathrm{K}$-feldspar grains.

\section{Na-feldspar}

To investigate whether the presence of Na-feldspar could result in a reduction of the apparent natural doses from slices, the equivalent doses recorded by Na-feldspar extracts from surface slices from three samples (099901, 099902, and 0999011) were measured. The results show that for samples 099901 and 099902 the doses measured using $\mathrm{Na}$ - and $\mathrm{K}$-feldspar grains are similar in magnitude and distribution $(19.8 \pm 8.8$ Gy [KF], $17.3 \pm 3.3$ Gy [NF], 099901; 35.5 \pm 9.7 Gy [KF], 37.5 \pm 8.9 Gy [NF], 099902). However, doses measured using Na-feldspar grains from sample 099911 were indeed much smaller than those measured using K-feldspar grains (mean $=8.22 \pm 3.18$ Gy and mean $=0.70 \pm 0.03$ Gy from K- and Na-feldspar grains respectively). Thomsen et al. (2008) report that there is no large difference between the bleaching and fading rates for $\mathrm{K}$ - and Na-feldspar extracts from sediments. It appears that the difference in surface doses for sample 099911 needs to be investigated further.

\section{BLEACHING WITH DEPTH}

The small doses measured using inverted surface slices showed that the effects of the attenuation of light through these solid rock samples is not significant at a depth of $\sim 1 \mathrm{~mm}$ from the surface. This suggests that the variation of luminescence signal with depth can be used to investigate the penetration of daylight into the rock surface (e. g. Polikreti et al., 2002). To test this hypothesis, a $\sim 30 \mathrm{~mm}$ long core was taken from of sample 099901 and another from 099902, and each cut into $\sim 1 \mathrm{~mm}$ thick slices. The corrected natural luminescence signals $\left(\mathrm{L}_{\mathrm{n}} / \mathrm{T}_{\mathrm{n}}\right)$ were then measured in the usual manner. Fig. 10 shows that for both samples the $L_{n} / T_{n}$ values (and thus the doses) increase smoothly with depth, with the more rapid increase in sample 099902.

Assuming that the rate of trapping due to natural radiation is negligible in comparison to the rate of detrapping due to bleaching, the dependence of the trapped charge 




Fig. 10. IRSL intensity as a function of depth in the rocks for samples 099901 and 099902 . Note that $y$-axis is in logarithmic scale. Solid and dashed curves are the fits to Eq 5.3 for samples 099901 and 099902 respectively. The inset shows the corrected IRSL for the first $10 \mathrm{~mm}$ on a linear scale.

(giving rise to the luminescence signal) on the flux of incident photons at a given depth $(x)$ can be approximated by:

$$
\mathrm{n}(\mathrm{x})=\mathrm{n}_{0} \mathrm{e}^{-\mathrm{t} \cdot \int_{\lambda \mathrm{i}}^{\lambda \mathrm{f}} \sigma(\lambda) \Phi(\lambda, \mathrm{x}) \mathrm{d} \lambda}
$$

Here $\mathrm{n}_{0}$ is the initial trapped charge population $\left(\mathrm{cm}^{-3}\right)$ assumed to be constant at all depths prior to bleaching, $\mathrm{n}$ is the trapped charge concentration $\left(\mathrm{cm}^{-3}\right)$ after the exposure time $\mathrm{t}(\mathrm{s}), \Phi$ is the photon flux (per $\mathrm{cm}^{2}$ per s), $\lambda(\mathrm{cm})$ is the incident wavelength $\left(\lambda_{f}\right.$ and $\lambda_{i}$ describing the upper and lower wavelength limits of the solar spectrum), and $\sigma$ $\left(\mathrm{cm}^{2}\right)$ is the photoionisation cross section (see Jain and Lindvold, 2007; note that we use flux here instead of fluence because we are interested in the light sum falling on a unit area).

The photon flux varies both with wavelength and depth. The relationship can be represented by:

$\Phi(\lambda, \mathrm{x})=\Phi(\lambda, 0) \mathrm{e}^{-\mu(\lambda) \mathrm{x}}$

where $\mu$ is the attenuation coefficient $\left(\mathrm{cm}^{-1}\right)$, and $x$ is the depth into the rock $(\mathrm{cm})$. If we assume, for simplicity, that light attenuation (or penetration) is not significantly dependent on wavelength in the spectral range of interest, then

$\Phi(\lambda, \mathrm{x})=\Phi(\lambda, 0) \mathrm{e}^{-\mu \mathrm{x}}$

Combining Eqs. 5.1 and 5.3, and assuming that luminescence $(L)$ is proportional to $\mathrm{n}$ gives

$\mathrm{L} \propto \mathrm{n}=\mathrm{n}_{0} \mathrm{e}^{-\mathrm{t} .} \int_{\lambda \mathrm{i}}^{\lambda \mathrm{f}} \sigma(\lambda) \Phi(\lambda, 0) \mathrm{e}^{-\mu \mathrm{x}} \mathrm{d} \lambda$

or

$\mathrm{L}=\mathrm{L}_{0} \mathrm{e}^{\overline{\sigma \Phi_{0}} \mathrm{te}} \mathrm{e}^{-\mu x}$

where $\overline{\sigma \Phi_{0}}=\int_{\lambda \mathrm{i}}^{\lambda \mathrm{f}} \sigma(\lambda) \Phi(\lambda, 0) \mathrm{d} \lambda$

The quantity $\overline{\sigma \Phi_{0}}$ defines the decay rate of the trapped charge (and thereby the luminescence) at the surface, when the sample is exposed to the solar spectrum. This simplified model of bleaching (Eq. 5.5) satisfactorily represents the experimental data (see fitted solid and dashed lines in Fig. 10). The two estimates 10 and 16 for the product $\overline{\sigma \Phi_{0}} \mathrm{t}$ are reassuringly similar for our two cores from the two different rocks, as would be expected for two surfaces having a similar history of daylight exposure. The attenuation factors $(\mu)$ of $0.8 \pm 0.2$ (099901) and $0.51 \pm 0.19 \mathrm{~mm}^{-1}$ (099902) indicate that it takes $\sim 3 \mathrm{~mm}$ and $\sim 4.5 \mathrm{~mm}$ of rock to attenuate the incident light intensity by $90 \%$ in these samples. This is comparable to the results reported by Habermann et al., (2000) which show an almost complete bleaching to a depth of at least $2 \mathrm{~mm}$ after several minutes of exposure to sunlight (Habermann et al., 2000).

Based on the $90 \%$ depletion curve (i.e. $\mathrm{L} / \mathrm{L}_{0}=0.1$ ) provided by Spooner (1994; Fig. 3), and Eq. 5.7 (derived from Eq. 5.1):

$\frac{\mathrm{L}}{\mathrm{L}_{0}}=0.1=\mathrm{e}^{-\sigma \Phi \mathrm{t}}$

the photoionisation cross sections $(\sigma)$ for feldspar can be approximated as a function of wavelength. The data of Spooner (1994) was extrapolated to the values up to $10 \mu \mathrm{m}$ assuming that the exponential relationship remains valid in this wavelength interval. The estimated cross sections were in the range $5.9 \times 10^{-17} \mathrm{~cm}^{2}(300 \mathrm{~nm})$ to $2.7 \times 10^{-86} \mathrm{~cm}^{2}(10 \mu \mathrm{m})$. The solar radiation spectrum at sea level is well approximated by the emission of a perfect black body at a temperature of $5800 \mathrm{~K}$ (Şen, 2008). This black body spectrum can be normalised to the average amount of solar energy received at the earth's surface $\sim 0.012 \mathrm{~W} / \mathrm{cm}^{2}$ averaged over the study region $\left(55^{\circ}-56^{\circ}\right.$ $\mathrm{N}, 12^{\circ}-13^{\circ} \mathrm{E}$ ) over a year (NASA, 2010) to give the wavelength dependent flux $\Phi(\lambda, 0)$ of photons at the earth's surface. Knowing the values of $\sigma(\lambda)$ and $\Phi(\lambda, 0)$, the products can be summed over the wavelength range $300 \mathrm{~nm}$ to $10 \mu \mathrm{m}$, at intervals of $5 \mathrm{~nm}$, to give $\overline{\sigma \Phi_{0}}$ (see Eq. 5.6). For $\overline{\sigma \Phi_{0}} \mathrm{t}=13$, the mean of our values obtained from Eq. 5.3 (Fig. 10), the calculated length of daylight exposure (t) becomes $\sim 30 \mathrm{~min}$. However, as visible light is unlikely to penetrate far into solid rock, it is interesting to consider the effect of ignoring the contribution of wavelengths $<700 \mathrm{~nm}$. Limiting our wavelength range from $700 \mathrm{~nm}$ to $10 \mu \mathrm{m}$, the exposure time increases to $\sim 3$ days which is still significantly less than the expected exposure time of many years for these samples. This discrepancy presumably arises because bleaching of feldspar luminescence is known not to be exponential for low residual signals. Thus the bleaching rate of the last part of these residual signals will have been much slower than that assumed in the model. 


\section{DISCUSSION AND CONCLUSIONS}

Our results confirm that while lack of sensitivity is likely to limit the application of quartz as a dosimeter in the luminescence dating of primary rock surfaces, the strong IRSL signal from feldspar suggests it as a more widely-applicable dosimeter. The equivalent doses from aliquots of K-feldspar grains extracted from surfaces were surprisingly large and scattered $(0.02$ to $>100 \mathrm{~Gy})$, and varied from sample to sample, despite our expectation that these surfaces had all received a similar and prolonged daylight exposure. However, the $D_{e}$ values recorded by solid slices $(\sim 1 \mathrm{~mm}$ thick) from the same surfaces were consistently small. Crushing, partial bleaching of the grains within the slices, and the contribution of Na-feldspar grains to the signals from the solid slices did not account for these discrepancies between grain extracts and solid slices, and the origins of these differences remain to be explained.

The residual doses left in both grains and solid slices after bleaching experiments using a solar simulator and IR diodes show that these laboratory methods for resetting the luminescence signal are not as effective as resetting in nature. In addition, we were unable to measure known doses administered after such laboratory bleaching to within $\sim 20 \%$. Nevertheless, the average residual $D_{e}$ estimates measured for naturally bleached surface slices was $0.17 \pm 0.02 \mathrm{~Gy}$; given the matrix dose rates of $\sim 6$ and $\sim 4.5 \mathrm{~Gy} / \mathrm{ka}$ for samples 099901 and 099902 respectively (Table 1), and a mean internal beta dose rate to a mixture of K-and Na-rich feldspar of a few Gy/ka (Mejdahl, 1979; depending on mean grain size) these doses suggest an apparent residual age of less than $\sim 40$ years.

Finally the variation of residual luminescence with depth suggests daylight is attenuated by about $90 \%$ at a depth of 3 to $4 \mathrm{~mm}$ into the solid surface of our samples. Since the luminescence resulting from any burial dose would be superimposed on this attenuation curve, it would seem possible to predict the residual dose prior to burial by modelling the dose/depth dependency of the luminescence signal. Thus, in principle, each buried rock surface contains a record of the completeness of bleaching prior to burial. From this point of view at least, the dating of the surfaces of large clasts has an inherent advantage over the dating of small grains. On the other hand, the problems of calculating the mean dose rate giving rise to an unknown mixture of feldspar signals remain considerable.

\section{ACKNOWLEDGMENT}

The author thanks two anonymous reviewers who helped improve this manuscript by their constructive comments.

\section{REFERENCES}

Aitken MJ, 1985. Thermoluminescnce dating. Academic Press. London. Blair MW, Yukihara EG, McKeever SWS, 2005. Experiences with single-aliquot OSL procedures using coarse-grain feldspar. Radiation Measurements 39(4): 361-374, DOI 10.1016/j.radmeas.2004.05.008.

Buylaert JP, Vandeberghe D, Murray AS, Huot S, De Corte F, Van den haute $P, 2007$. Luminescence dating of old ( $>70 \mathrm{ka})$ Chinese loess: A comparison of single-aliquot OSL and IRSL techniques. Quaternary Geochronology 2(1-4): 9-14, DOI 10.1016/j.quageo.2006.05.028.

Buylaert JP, Murray AS, Thomsen KJ, Jain M, 2009. Testing the potential of an elevated IRSL signal from K-feldspar. Radiation Measurements 44 (5-6): 560-565, DOI 10.1016/j.radmeas.2009.02.007.

Bøtter-Jensen L, Andersen CE, Duller GAT, Murray AS, 2003. Developments in radiation, stimulation and observation facilities in luminescence measurements. Radiation Measurements 37(4-5): 535541, DOI 10.1016/S1350-4487(03)00020-9.

Jain M, Lindvold LR, 2007. Blue light stimulation and linearly modulated optically stimulated luminescence. Ancient TL 25 (2): 69-80.

Greilich S, Glasmacher UA, Wagner GA, 2005. Optical dating of granitic stone surfaces. Archaeometry 47 (3): 645-665, DOI 10.1111/j.1475-4754.2005.00224.x.

Habermann J, Schilles T, Kalchgruber R, Wagner GA, 2000. Steps towards surface dating using luminescence. Radiation Measurements 32(5-6): 847-851, DOI 10.1016/S1350-4487(00)00066-4.

Hunley DJ, Lamothe M, 2001. Ubiquity of anomalous fading in Kfeldspars and the measurement and correction for it in optical dating. Canadian Journal of Earth Sciences 38: 1093-1106. DOI 10.1139/cjes-38-7-1093.

Klasen N, Fiebig M, Preusser F, Radtke U, 2006. Luminescence properties of glaciofluvial sediments from the Bavarian Alpine Foreland. Radiation Measurements 41(7-8): 886-870, DOI 10.1016/j.radmeas.2006.05.016.

Liritzis I, 1994. A new dating method by thermoluminescence of carved megalithic stone building. Comptes Rendus de l'Académie des Sciences-Série II 319: 603-610.

Liritzis I, Guibert P, Foti F, Schvoerer M, 1997. The temple of Apollo (Delphi) strengthens novel thermoluminescence dating method. Geoarchaeology 12(5): 479-496, DOI 10.1002/(SICI)15206548(199708)12:5<479::AID-GEA3>3.0.CO;2-X.

Liritzis I and Galloway RB, 1999. Dating implications from solar bleaching of thermoluminescence of ancient marble. Journal of Radioanalytic and Nuclear Chemistry 241(2): 361-368, DOI 10.1007/BF02347476.

Liritzis I, Sideris C, Vafiadou A, Mitsis J, 2007. Mineralogical, petrological and radioactivity aspects of some building material from Egyption Old Kingdom monuments. Journal of Cultural Heritage 9(1): 1-13, DOI 10.1016/j.culher.2007.03.009.

Liritzis I, Kitis G, Galloway RB, Vafiadou A, Tsirliganis NC, Polymeris G, 2008. Probing luminescence dating of archaeologically significant carved rock types. Mediterranean Archaeology and Archaeometry 8 (1): 61-79.

Madsen AT and Murray AS, 2009. Optically stimulated dating of young sediments: A review. Geomorphology 109(1-2): 3-16, DOI 10.1016/j.geomorph.2008.08.020.

Mejdahl V, 1979. Thermoluminescence dating: beta-dose attenuation in quartz grains. Archaeometry 21(1): 61-72, DOI 10.1111/j.14754754.1979.tb00241.x.

Morgenstein ME, Luo S, Ku TL, Feathers J, 2003. Uranium-series and luminescence dating of volcanic lithic artefacts. Archaeometry 45(3): 503-518, DOI 10.1111/1475-4754.00124.

Moska P, Murray AS, 2006. Stability of the quartz fast-component in insensitive samples. Radiation Measurements 41(7-8): 878-885, DOI 10.1016/j.radmeas.2006.06.005.

Murray AS, Marten R, Johnston A, Martin P, 1987. Analysis for naturally occurring radionuclides at environmental concentrations by gamma spectrometry. Journal of Radioanalytical and Nuclear Chemistry 115(2): 263-288, DOI 10.1007/BF02037443. 
Murray AS, Wintle AG, 2000. Luminescence dating of quartz using an improved single-aliquot regenerative-dose protocol. Radiation Measurements 32(1): 57-73, DOI 10.1016/S1350-4487(99)00253$\mathrm{X}$.

NASA, 2010. NASA surface metrology and solar energy. http://eosweb.larc.nasa.gov/cgi-bin/sse/grid.cgi.

Polikreti K, Michael CT, Maniatis Y, 2002. Authenticating marble sculpture with thermoluminescence. Ancient TL 20(1): 11-18.

Polikreti K, Michael CT, Maniatis Y, 2003. Thermoluminescence characteristics of marble and dating of freshly excavated marble objects. Radiation Measurements 37(1): 87-94, DOI 10.1016/S1350-4487(02)00088-4.

Spooner NA, 1994. The anomalous fading of infrared-stimulated luminescence from feldspars. Radiation Measurements 23(2-3): 625632, DOI 10.1016/1350-4487(94)90111-2.

Şen Z, 2008. Solar energy fundamentals and modelling techniques. Springer. London.

Theocaris PS, Liritzis I, Galloway RB, 1997. Dating of two Hellinic Pyramids by a novel application of thermoluminescence. Journal of Archaeological Science 24(5): 399-405, DOI 10.1006/jasc.1996.0124.
Thomsen KJ, Murray AS, Jain M, Bøtter-Jensen L, 2008. Laboratory fading rates of various luminescence signals from feldspar-rich sediment extracts. Radiation Measurements 43(9-10): 1474-1486, DOI 10.1016/j.radmeas.2008.06.002.

Tsukamoto S, Nagashima K, Murray AS, Tada R, 2011. Variations in OSL components from quartz from Japan sea sediments and the possibility of reconstructing provenance. Quaternary International 234(1-2): 182-189, DOI 10.1016/j.quaint.2010.09.003.

Vafiadou A, Murray AS, Liritzis I, 2007. Optically stimulated luminescence (OSL) dating investigations of rock and underlying soil from three case studies. Journal of Archaeological Science 34(10): 1659-1669, DOI 10.1016/j.jas.2006.12.004.

Wallinga J, Murray AS, Duller GAT, 2000. Underestimation of equivalent dose in single-aliquot optical dating of feldspars caused by preheating. Radiation Measurements 32(5-6): 691-695, DOI 10.1016/S1350-4487(00)00127-X

Wallinga J, Bos AJJ, Dorenbos P, Murray AS, Schokker J, 2007. A test case for anomalous fading correction in IRSL dating. Quaternary Geochronology 2(1-4)

10.1016/j.quageo.2006.05.014
216-221,

DOI 